\section{Argentinian release}

Reports coming out of Argentina indicate that most of the employees of the Atomic Energy Commission who have been in prison since April (Nature, October 7, page 452) have now been released. Dr T. Victoria, whose brother highlighted their problems, is now in Belgium; the rest are still in Buenos Aires. There is, however, still no news at all of Antonio Misetich, a one-time MIT researcher.

\section{UK physicists' concern}

The UK high energy physics community is becoming increasingly concerned at the prospect of financial setbacks to its research effort. This became clear last week with the emergence of attempts to organise its members for concerted action. These follow the Science Research Council's recent urgent request to large laboratories for information on possible early cutbacks in expenditure.

One possibility being canvassed is that there should be a letter-writing campaign to ministers, MPs and the Advisory Board of the Research Councils, which has pursued a deliberate policy of squeezing big science. Another is that the most distinguished members of the nuclear and highenergy physics community might be able to agree on some form of corporate action to defend their interests.

The government's cash limits doctrine, which with a depreciating pound strains the SRC's international obligations, has precipitated the crisis.

\section{FBR decision postponed}

Britain's decision whether to build a demonstration commercial fast breeder reactor, due this autumn, has been delayed to give more time for public debate. Mr Anthony Wedgwood Benn, the UK Energy Secretary, has also indicated that the questions put last week to the Nuclear Installations Inspectorate concerning the fast breeder are designed to assess its margins of safety independently for the public's benefit. France's Phénix prototype fast breeder at Marcoule closed down recently for a period of weeks because of a leak in one of its heat exchangers.

\section{Ariel V's birthday}

The UK's Appleton Laboratory celebrated the Ariel V satellite's second anniversary on October 15. Ariel V, launched off the coast of Kenya, is controlled from the Appleton Laboratory which rapidly transmits data to experimental groups at the universities of London (University College and Imperial College), Leicester and Birmingham; the Goddard Space Flight Center in Maryland also operates one of the experiments.
DoEs science, or do scientists, have a special responsibility to society? A conference held early in October in Florence, Italy, and organised by the Fondazione Internazionale Menarini, considered this subject from a number of angles. Experts from many countries gave papers on the problems arising from genetic engineering, ecological contamination of the biosphere, world food shortages, safer drugs for better therapy, the specific needs of developing countries and population overgrowth. The speakers identified many fields in which scientific research and its application obviously have an important part to play. They suggested that the public and their rulers often underestimate the contributions that scientists may make. But the general conclusion seemed to be that though scientists should be more vocal about their possible value, they should generally advise their rulers and should not formulate policy. In fact, they should continue to be "on tap, not on top".

Most speakers stressed the importance of work aimed at solving practical problems of food and health, and the need of more support for such investigations. However, others suggested that the important and soluble problems might not be so easy to identify, and they justified their efforts in more basic fields. For instance, it was said (predictably, by scientists with world reputations in the subject) that we know so little about the processes going on in the oceans that all manner of apparentlyacademic studies are justified in the hope that we may, eventually, have the knowledge to control marine pollution. It was interesting to hear views so reminiscent of the "Haldane principle" on which governmentsupported research in Britain was based until its recent reorganisation.

I could not help wondering how personally responsible were the scien-

\section{On responsibility}

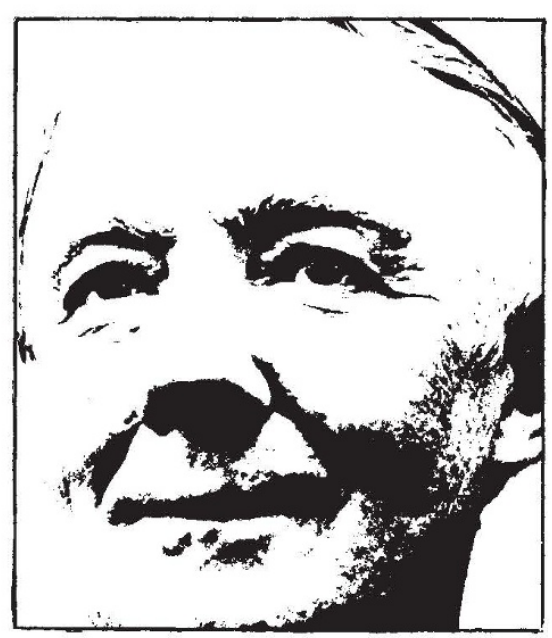

KENNETH MELLANBY

tists who were discussing responsibility. I found it interesting to observe the behaviour of many of the participants at this meeting. They had been transported freely from the ends of the earth, to be lavishly entertained by their Italian hosts, not only to the best of the food and wine of the country, but also, between sessions, to the art and music of Florence. I regret to have to report that I have seldom attended a meeting at which such a substantial number of the delegates put in such a poor attendance. Many appeared to feel that so long as they read a twenty minute paper (replete, in many cases, with material familiar to their meagre audience) and listened to a few of the other speakers at the same session, they were free to slip off to attend the "ladies" sightseeing tours or to go shopping or indulge in other nonscientific activities. This hardly seemed an example of scientific responsibility; surely delegates attending a conference at someone else's expense should be prepared to attend most of the meetings and contribute to the proceedings?

So is doing good work in the laboratory and attending meetings conscientiously the sum total of the scientists' responsibility to society? Our Marxist colleagues do not think so; it was a relief at the Florence meeting to be spared their diatribes urging the adoption of political dogmas as the acme of scientific fulfilment. I do not think I am alone in my belief that scientists are responsible not only for their own work, but for trying to ensure that this work, and that of their colleagues, is effectively organised and applied. If we are right in our views that many recent developments in scientific organisation have been harmful to both science and to society, it is our responsibility to try to have a better system adopted. We should do this no matter how unpopular it may make us with some of those in authority, and even though, under the present system, we depend on those same authorities for both support and (in the case of our younger members) the furtherance of our careers. 